\title{
A mathematical model of the interaction between bovine blastocyst developmental stage and progesterone-stimulated uterine factors on differential embryonic development observed on Day 15 of gestation
}

\author{
Paul R. Shorten,, ${ }^{* 1}$ Anita M. Ledgard, ${ }^{*}$ Martyn Donnison, ${ }^{*}$ Peter L. Pfeffer, $†$ Robin M. McDonald, ${ }^{*}$ \\ and Debra K. Berg* \\ *AgResearch Ltd., Ruakura Research Centre, Private Bag 3123, Hamilton 3240, New Zealand \\ †School of Biological Sciences, Victoria University of Wellington, Wellington 6140, New Zealand
}

\begin{abstract}
A complex interaction between the developing bovine embryo and the growth potential of the uterine milieu it inhabits results in an embryo capable of developing past the maternal recognition stage and on to a successful pregnancy. Previously, we observed variation in the lengths of embryos recovered $8 \mathrm{~d}$ after bulk transfer of Day 7 in vitro-produced (IVP) blastocysts into the same uterus. Potential causes of the differential embryonic growth were examined and modeled using 2 rounds of bulk ( $\mathrm{n}=4-6)$ IVP transfers and recovery of these embryos $8 \mathrm{~d}$ later. Morphological and gene expression measurements of the embryos were determined and the progesterone concentration of the cows was measured throughout the reproductive cycle as a reflection of the status of the uterine environment. These data were used to develop and evaluate a model that describes the interaction between the uterine environment and the growth rate of the developing embryo. Expression of 6 trophectoderm genes (IFNT, TKDP1, PAG11, PTGS2, DKK1, and PDPN) was correlated with conceptus length. The model determined that if the embryo develops to blastocyst stage, the uterine environment, driven by progesterone, is a more important component than blastocyst size in the stimulation of embryonic growth rate to ensure adequate interferon tau (IFNT) for pregnancy recognition. We detected an effect of Day 7 progesterone on the expression of all 6 genes, embryonic disc size, and trophectoderm length on Day 15. We also found effects of embryo transfer size on trophectoderm length and expression of IFNT and PAG11 on Day 15. Lower energy balance over the period from transfer to recovery was associated with reduced embryo growth to Day 15, and this effect was independent of progesterone. Energy balance also af-
\end{abstract}

Received March 7, 2017.

Accepted September 1, 2017.

${ }^{1}$ Corresponding author: paul.shorten@agresearch.co.nz fected expression of PDPN and TKDP1 on Day 15. We observed an effect of energy balance from transfer to recovery on embryo survival in cows with partial embryo losses, where embryo factors dominate embryo survival, with cows with greater energy balance having lower embryo losses. This effect was independent of energy balance $40 \mathrm{~d}$ before transfer and suggests that energy balance has direct, immediate effects on the embryo and maternal environment during this period. Furthermore, energy balance effects on embryo survival in cows with partial embryo losses were largely mediated by expression of TKDP1, PAG11, and PDPN. These results provide candidate signaling pathways for the effect of progesterone and energy balance on embryo growth and survival.

Key words: embryonic disc, embryonic growth model, interferon tau, uterine environment

\section{INTRODUCTION}

The developing ruminant conceptus is dependent on maternally derived factors including amino acids, cytokines, glucose, and growth factors present in the uterine luminal fluid for its growth and development beyond Day 7 . These maternally derived factors are crucial for successful elongation of the blastocyst and have not yet been replicated successfully using in vitro production (IVP) techniques (Brandão et al., 2004; Machado et al., 2013). The importance of uterine gland secretions into the histotroph has been demonstrated by the ablation of uterine gland development in the perinatal ewe, resulting in a maternal environment in which embryos fail to successfully elongate (Gray et al., 2002). The environment of the developing embryo is an essential regulator of interferon tau (IFNT) production, which overrides luteolytic mechanisms to allow the establishment and maintenance of pregnancy (Spencer et al., 2007). Early in the estrous cycle, the secretion of uterine proteins into the lumen changes as the hormone profile changes. Progesterone is one of the main regula- 
tors of the genes expressed in the endometrium that are involved in the preparation of the uterus during early pregnancy (Bazer et al., 1979; Spencer et al., 2004) and this is reflected in the protein expressed in the uterine histotroph (Ledgard et al., 2012; Forde et al., 2014). In beef heifers, elevation of progesterone concentrations on Days 5 and 7 after estrus results in an increase in the size of the conceptus at Day 16 (Garrett et al., 1988; Carter et al., 2008) and it appears that the altered histotroph composition produces this effect rather than a direct effect of progesterone on the embryo (Clemente et al., 2009). Lactating cows have lower serum progesterone concentrations throughout the cycle compared with heifers (Rizos et al., 2010), possibly because of the reported faster rate of metabolism of progesterone in lactating cows compared with nonlactating cows (Sangsritavong et al., 2002). Embryonic mortality due to the uterine environment is as high as $13 \%$ for cows compared with 3\% in heifers (Berg et al., 2010). Several factors other than progesterone may influence the difference in uterine luminal fluid composition, including nutrition and metabolic state of the animal (Roche et al., 2011). The combination of these factors will result in a downstream modulating effect on uterine protein levels present in the luminal fluid, which can be specific to individual animals (Ledgard et al., 2011). One mode of action of the uterine influence may be on the metabolic growth rate of embryos, because it has been shown that Day 18 embryos recovered from heifers had more active biosynthetic pathways than those derived from lactating cows (Valour et al., 2014).

However, the embryo also contributes to the complexity of events that occur during preimplantation and this ultimately affects pregnancy outcome (Ulbrich et al., 2012). Approximately $5 \%$ of embryos die because of gross chromosomal abnormalities that prevent development (Peters, 1996), and oocyte developmental competence varies depending on which category of follicular environment they have been derived from (Pavlok et al., 1992; Lonergan et al., 1994). As early as 1980, researchers reported variable length in bovine embryos recovered $15 \mathrm{~d}$ after superovulation from the same heifer (Betteridge et al., 1980). Those authors retransferred embryos with a range of sizes to recipients, which resulted in pregnancies from embryos as small as $2 \mathrm{~mm}$ on transfer to the largest (18 $\mathrm{mm}$ ) embryo transferred; however, the input of the recipient was not well defined. We have noted in our previous studies that a range of conceptus lengths may be recovered from the same cow on gestational Day 14 or 15 from bulk transfer of IVP blastocysts (Berg et al., 2010). The trophectoderm can continue to elongate in vivo even without the embryonic disc, as demonstrated in a study where the discs were excised from tubular conceptuses before their transfer to a recipient (Fléchon et al., 1986). However, those cultured in vitro did not elongate further. As the amount of IFNT secreted by the embryo is consistent with the size of the trophectoderm tissue (Robinson et al., 2006), the amount of IFNT present in the uterus available to signal pregnancy is therefore dependent on the growth rate of the embryo.

In this study, we examined in detail the development of embryos on Day 15 using bulk transfer ( $\mathrm{n}=4$ to 6 per cow) of Day 7 IVP blastocysts. Developmental differences between those nurtured in different maternal environments and any disparate development of those supported in an identical uterine environment (i.e., the same cow) were examined. The conceptus length, its trophectoderm gene expression, and embryonic disc development were compared to determine developmental variability. A mathematical model is proposed to calculate the early pre-attachment embryonic growth rate, encompassing both the embryonic and maternal factors.

\section{MATERIALS AND METHODS}

\section{Animals}

All experimental procedures were undertaken in accordance with the regulations of the New Zealand Animal Welfare Act of 1999 under Ruakura Animal Ethics Committee approval AE12652. High breeding value Friesian cows $(\mathrm{n}=37)$ in their second lactation were used to compare IVP embryo development at gestational Day 15 within the same uterine environment. The cows were maintained at the AgResearch Tokanui Farm under normal pastoral "best farm practice" grazing herd management plus silage as required to achieve a BCS of 5 (10-point scale) before calving. Following calving, the cows were subjected to various milking frequencies $(0,1$, or 3 times per day), with feed intake and exercise manipulated to reduce the variation in BCS throughout the experiment. The animals were under veterinarian supervision throughout the experiment.

\section{Sequential Embryo Transfer and Recovery}

At approximately 28 to $30 \mathrm{~d}$ postpartum, the estrous cycles of the cows were synchronized using controlled internal drug releasing (CIDR) inserts (Zoetis, Auckland, New Zealand). The CIDR was inserted for a total of 12 $\mathrm{d}$, with a single injection of a prostaglandin $\mathrm{F}_{2 \alpha}$ analog (2 $\mathrm{mL}$ of $250 \mathrm{mg} / \mathrm{mL}$ cloprostenol sodium; Estroplan, Parnell Technologies, Alexandria, Australia) given on d 8. At the time of CIDR removal, cows were tail-painted and observed for estrous behavior, and an initial IVP transfer was performed on Day 7 after standing estrus 
(Day 0). Standard laboratory procedures were followed to generate IVP embryos (Berg et al., 2010), taking care to use ovaries from beef-Friesian cross heifers and frozen-thawed spermatozoa from one Friesian bull throughout the entire in vitro production. Different stage and grade blastocysts (early, $\mathrm{n}=5$; normal grade $1, \mathrm{n}=13$; normal grade $2, \mathrm{n}=25$; expanded grade $1, \mathrm{n}$ $=57$; expanded grade $2, \mathrm{n}=56$; hatched blastocysts, $\mathrm{n}$ $=2$ ) were selected for transfer on the basis of morphologic evaluation by the same experienced embryologist throughout the entire transfer period. From 4 to 6 of these blastocysts were bulk-transferred transcervically, ensuring that blastocysts with a mix of morphologies as even as possible were received by each recipient cow (each category had different numbers of blastocysts so a perfect match could not be achieved).

Eight days after transfer, both the ipsilateral and contralateral uterine horns were nonsurgically flushed using an 18- or 20-French Foley 2-way embryo collection catheter as previously reported (Berg et al., 2010), and the contents of both uterine horns were collected into the same collection bottle. These embryos had their origin (cow) recorded and total length measured using an eyepiece graticule or a transparent ruler. In cases where embryos recovered were fragmented $(25 \%)$, the actual number of embryos was confirmed by counting the visible ends under a stereomicroscope. They were also examined for the presence of an embryonic disc/ epiblast (ED), which was photographed using a Nikon SMZ1500 microscope and DsFi1 camera (Nikon Instruments, Tokyo, Japan), and the total length and width of any ED were measured using a graticule. The ED area was calculated as the area of an ellipse $(\pi \times$ length $\times$ width/4). The ED were excised, the corresponding trophectoderm (TE) was placed in TRIzol (Invitrogen, Carlsbad, CA), and samples were stored at $-80^{\circ} \mathrm{C}$ until processed.

This experiment was repeated with a second IVP transfer at $86 \mathrm{~d}$ postpartum into the same recipient cows after a prostaglandin estrous synchronization, with the initial injection given at the time of embryo recovery from the first embryo transfer. A single injection of $\mathrm{GnRH}$ was given to induce ovulation $3 \mathrm{~d}$ later (d 0 ) and the second $\mathrm{PGF}_{2 \alpha}$ injection given on $\mathrm{d} 12$ to 15 of the subsequent estrous cycle. In this round, normal grade 1 and 2, expanded grade 1 and 2, and hatched blastocyst morphologies $(\mathrm{n}=10,17,68,64$, and 11 , respectively) were bulk transferred $(\mathrm{n}=5$ per cow) with an even mix of morphologies (to the extent possible) received by each recipient cow on the seventh day after expected estrus (d 0 ), as previously detailed. The embryos were collected using the same procedures as previously outlined.

\section{Progesterone Assay}

Blood was sampled from the tail vein into evacuated heparinized blood tubes (Vacutainer; Becton Dickinson, Auckland, New Zealand) on Days 2, 5, 7, and 15 of the embryo flush cycles for progesterone measurement. Blood samples were placed immediately in ice water, and then centrifuged at $4^{\circ} \mathrm{C}$ for $15 \mathrm{~min}$ at $1,500 \times \mathrm{g}$. Aspirated plasma was stored at $-20^{\circ} \mathrm{C}$ until assayed.

Progesterone concentrations were measured with an electro chemiluminescence detection system (Elecsys Progesterone II kits, Roche Diagnostics GmbH, Mannheim, Germany) using an automated clinical immunology analyzer (Roche Modular E170, HoffmannLa Roche Ltd., Basel, Switzerland) at New Zealand Veterinary Pathology Ltd. (Hamilton, New Zealand). The sensitivity of the assay was $0.03 \mathrm{ng} \cdot \mathrm{mL}^{-1}$ and the co-efficient of variation was $<5 \%$. Only one sample had a concentration $<0.03 \mathrm{ng} \cdot \mathrm{mL}^{-1}$, and this measurement was assigned the value of the sensitivity of the assay $\left(0.03 \mathrm{ng} \cdot \mathrm{mL}^{-1}\right)$.

\section{Mathematical Model of Embryo Development}

The mathematical model of embryo development combined the complex interaction between progesterone, which influences the uterine environment, and blastocyst developmental stage on transfer to the uterus. The model is based on the major biological mechanisms underlying embryo growth in the literature.

The rate of change in the circulating progesterone concentration $\left(\boldsymbol{P} ; \mathrm{ng} \cdot \mathrm{mL}^{-1}\right)$ is

$$
\frac{\mathrm{d} P}{\mathrm{~d} t}=k P\left(P_{\max }-P\right), \quad P(0)=P_{0},
$$

where $k$ is the rate of progesterone production $\left(\mathrm{ng}^{-1} \cdot \mathrm{mL} \cdot \mathrm{d}^{-1}\right), t$ is time from ovulation $(\mathrm{d}), P_{0}$ is the progesterone concentration on $\mathrm{d} 0\left(\mathrm{ng} \cdot \mathrm{mL}^{-1}\right)$, and $P_{\max }$ is the maximum progesterone concentration (Shorten et al., 2010). This model describes the characteristics of the progesterone dynamics during the cycle (Tsai and Wiltbank, 1998).

The production of IFNT is low during the first $13 \mathrm{~d}$ of pregnancy but by Day 15, there is a surge in IFNT production. The time and intensity of the IFNT signal can be modified by progesterone (Satterfield et al., 2006). This modification is caused by progesteroneinduced changes in the uterine environment rather than a direct effect on the embryo (Clemente et al., 2009). Elevated progesterone concentrations during the early luteal phase positively correlate with embryo survival, whereas low progesterone decreases survival (Diskin and Morris, 2008; Clemente et al., 2009). To account 
for this effect, we defined a function $h(t)$ (unitless) that describes uterine competence and is described by

$$
h(t)=a P(t-b),
$$

where $a$ represents the intensity of the effect of progesterone on the competence of the endometrium $\left(\mathrm{ng}^{-1} \cdot \mathrm{mL}\right), b$ represents the time delay between circulating progesterone and uterine competence $(\mathrm{d}), t$ is time from ovulation (d), and $P(s)$ is the concentration $\left(\mathrm{ng} \cdot \mathrm{mL}^{-1}\right)$ of progesterone at time $s$.

Normally, the embryo takes approximately $5 \mathrm{~d}$ to travel from the fallopian tube to the uterus, where embryo growth is determined by the competence of the uterine environment (our results are not dependent on the value of $5 \mathrm{~d}$ ). The rate of change in the embryo developmental stage $(A)$ is described by

$$
\frac{\mathrm{d} A}{\mathrm{~d} t}=h_{1}[1-H(t-5)]+h(t)^{n} \times H(t-5), \quad A(5)=A_{5},
$$

where $A_{5}$ is the embryo developmental stage on Day 5 ( $\log _{10}$ cell number), $h_{1}$ is the rate of embryo development $\left(\log _{10}\right.$ cell number $\left.\cdot \mathrm{d}^{-1}\right), n$ describes the nonlinear relationship between progesterone and embryo development (unitless), and $H(t)$ denotes the Heaviside switch function:

$$
H(t)=\left\{\begin{array}{ll}
1, & t \geq 0 \\
0, & t<0
\end{array} .\right.
$$

Developmental stage is defined by $\log _{10}$ cell number before blastocyst hatching and by embryo length $(\mathrm{mm})$ after blastocyst hatching, with embryo size increasing exponentially from Day 1 to blastocyst hatching on Day 9 (Ushijima et al., 2009). The cell doubling time from Day 5 is therefore inversely proportional to $h(t)^{n}$ (if $n=0.33$, then doubling progesterone decreases the doubling time by 20\%).

Embryo length increases exponentially from blastocyst hatching on Day 9 (Morris and Diskin, 2008; Berg et al., 2010). The rate of change in the $\log _{10}$ embryo length $\left(L ; \log _{10} \mathrm{~mm}\right)$ is described by

$$
\frac{\mathrm{d} L}{\mathrm{~d} t}=+g h(t)^{n}, \quad L\left(t_{H}\right)=L_{H}, \quad A\left(t_{H}\right)=A_{H}, \quad[5]
$$

where embryo elongation is initiated at developmental stage $A_{H}\left(\log _{10}\right.$ cell number) at time $t_{H}$ (days), $n$ describes the nonlinear relationship between progesterone and embryo elongation, and $g$ is a measure of the rate of embryo elongation $\left(\log _{10} \mathrm{~mm} \cdot \mathrm{d}^{-1}\right)$. The number of cells and length of a blastocyst at the time of hatching have been estimated (Berg et al., 2010; Spencer, 2013) and we assume that $L_{H}=\log _{10}(0.3) \log _{10} \mathrm{~mm}$ and $A_{H}=$ $\log _{10}(512) \log _{10}$ cells.

The size of each transferred blastocyst was not measured, and representative sizes were based on criteria derived from superovulated embryos, where the blastocyst stages were early (range 63-101 cells, mean 78.2 cells), normal (range 97-129 cells, mean 117.6 cells), expanding (range 142-193 cells, mean 159.2 cells), hatching (range 195-235 cells, mean 219.8 cells; Ushijima et al., 2009). Normal and expanding blastocysts were further classified as small or large and this was assumed to be based on the midpoint of the $\log _{10}$ cell number range (range 97-112 cells, mean 104.2; range 113-129 cells, mean 120.7 ; range $142-170$ cells, mean 155.4; range 171-193 cells; mean 181.7). These sizes conform to exponential growth in embryo cell number and the estimated rate of embryo development $\left(h_{1}\right)$ is interpreted on this scale.

\section{Mathematical Model of Embryo Survival}

Several models of embryo survival exist in the literature and are described in detail below. Each model is based on a set of assumptions on the biology.

Binomial Model. Embryo survival is described by the probability $(p)$ that an embryo survives from Day 7 to Day 15. The survival of embryos over this interval is assumed independent of the survival of other embryos (Berg et al., 2010). Embryo survival from Day 7 to Day 15 is therefore a binomial random variable. The probability that $k$ out of $n$ embryos survive in a cow $(Q)$ is

$$
Q(k ; n, p)=\frac{n !}{k !(n-k) !} p^{k}(1-p)^{n-k},
$$

where $\frac{n !}{k !(n-k) !}$ is the number of possible ways of choosing $k$ embryos from $n$.

Mixed-Binomial Model. The mixed-binomial model generalizes the binomial model (Restall and Griffiths, 1976). If the embryo survival probability $(p)$ is a random variable (but constant for each cow) with $E(p)=a$, where $E(p)$ denotes the expected value of the random variable $\mathrm{p}$, and $E\left(p^{2}\right)=b\left[\operatorname{Var}(p)=b-a^{2}\right]$, then the probability that $k$ out of $n$ embryos survive in a cow is

$$
\begin{aligned}
Q(k ; n, p) & =\frac{n !}{k !(n-k) !} p^{k}(1-p)^{n-k} \\
p & \sim N\left(a, b-a^{2}\right)
\end{aligned}
$$


where $N\left(\mu, \sigma^{2}\right)$ represents the normal distribution with mean $\mu$ and variance $\sigma^{2}$. The variance in embryo survival probability $[\operatorname{Var}(p)]$ is the sum of a cow variance component $\left(\sigma_{C}^{2}\right)$ and an embryo sampling variance component $\left(\sigma_{E}^{2} / n\right)$. We note that the variance in the uniform probability distribution is $1 / 12$, so that $\sigma_{E}<$ 0.289 .

McMillan and Restall and Griffiths Model. The McMillan (1998) and Restall and Griffiths (1976) model allows for a subset of cows that are not able to maintain an embryo irrespective of the quality of the embryo. The probability that a cow is able to maintain an embryo is $r$ [i.e., if there are $N$ cows, then $(1-r) N$ cows are not able to maintain an embryo] and such cows are termed "receptive." Cow receptiveness is therefore a Bernoulli random variable. This model allows both uterine receptiveness and embryo quality factors to be described and allows these dual components of the biology to be analyzed (Berg et al., 2010). The probability that $k$ out of $n$ embryos survive in a cow is

$$
Q(k ; n, p, r)=(1-r) \delta(k)+r \frac{n !}{k !(n-k) !} p^{k}(1-p)^{n-k},
$$

where $\delta(k)=1$ if $k=0$ and $\delta(k)=0$ if $k \geq 1$, the probability that a cow is able to maintain a pregnancy is $r$, and $p$ is a measure of embryo viability. It is assumed that the viabilities of individual embryos in the same uterus are independent. It is important to note that this model can be interpreted as a special case of the mixed-binomial model when $a=p r$ and $b=p^{2} r$.

Mixed McMillan and Restall and Griffiths Model. The McMillan model can be extended to allow for variability in embryo viability between animals. The probability that $k$ out of $n$ embryos survive in a cow is

$$
\begin{aligned}
Q(k ; n, p, r) & =(1-r) \delta(k)+r \frac{n !}{k !(n-k) !} p^{k}(1-p)^{n-k} \\
p & \sim N\left(\tilde{p}, \tau^{2}\right)
\end{aligned}
$$

where $\delta(k)=1$ if $k=0$ and $\delta(k)=0$ if $k \geq 1$, the probability that a cow is able to maintain a pregnancy is $r$, $N\left(\mu, \sigma^{2}\right)$ is the normal distribution with mean $\mu$ and variance $\sigma^{2}, \tilde{p}$ is the expected embryo viability, and $\tau^{2}$ is the variance in embryo viability. This model is a special case of the mixed-binomial model when $r=1$.

Progesterone-Dependent Embryo Survival Model. The mixed McMillan model can be extended to allow for progesterone-dependent effects on embryo viability. The probability that $k$ out of $n$ embryos survive in a cow is

$$
\begin{aligned}
Q\left(k ; n, p, r, P\left(t_{P}\right)\right) & =(1-r) \delta(k)+r \frac{n !}{k !(n-k) !}\left(p_{*}\right)^{k}\left(1-p_{*}\right)^{n-k} \\
p_{*} & =p+\beta_{p, 1} P\left(t_{P}\right)+\beta_{p, 2} P\left(t_{P}\right)^{2}+\beta_{E B} E B \\
& +\beta_{A 7} A_{7}+\sum_{i=1}^{M} \beta_{\text {gene }_{i}} \text { gene }_{i} \\
p & \sim N\left(\tilde{p}, \tau^{2}\right)
\end{aligned}
$$

where $\delta(k)=1$ if $k=0$ and $\delta(k)=0$ if $k \geq 1$, the probability that a cow is able to maintain a pregnancy is $r$, $N\left(\mu, \sigma^{2}\right)$ is the normal distribution with mean $\mu$ and variance $\sigma^{2}, P\left(t_{P}\right)$ is the progesterone concentration at time $t_{P}$ defined by Eq. [1], $\tilde{p}$ is the expected embryo viability, $\tau^{2}$ is the variance in embryo viability, $\beta_{p, 1}, \beta_{p, 2}$ denote linear and quadratic coefficients for the effect of progesterone on embryo viability, EB is energy balance $\left(\mathrm{MJ} \cdot \mathrm{d}^{-1}\right), \beta_{E B}$ denotes the linear effect of energy balance on embryo viability, $A_{7}$ is the developmental stage of the transferred embryo on Day 7 ( $\log _{10}$ cell number), and $\beta_{A 7}$ denotes the effect of the developmental stage of the transferred Day 7 embryo on embryo viability, gene denotes the Day 15 embryo gene expression for the $i$ th gene $\left[\log _{10}\left(\right.\right.$ relative copy number $\left.\left.\times 10^{3}\right)\right], \beta_{\text {gene }_{i}}$ denotes the effect of Day 15 gene expression for the $i$ th gene on embryo viability, and $M$ denotes the number of measured genes. This model can be readily extended to include other factors (continuous or categorical) that regulate embryo viability. The progesterone-dependent regression coefficients are sufficiently small that a logistic transformation is not required in the model.

\section{Modeling Energy Balance}

Cow daily energy balance $\left(\mathbf{E B} ; \mathrm{MJ}^{-1} \mathrm{~d}^{-1}\right)$ was calculated according to a modification of the procedure detailed in Pryce et al., (2006). The method was modified so that changes in BCS and liveweight both affect energy balance (AFRC 1993, Gregory et al., 1998). Daily EB $\left(\mathrm{MJ} \cdot \mathrm{d}^{-1}\right)$ on day $t$ was calculated as

$$
E B_{t}=\text { MEintake }_{t}-\left(\begin{array}{l}
\text { MEexercise }_{t}+\text { MEmain }_{t}+\text { MEmilk } \\
t \\
+ \text { MEbcs }_{t}+M E b c n f_{t}
\end{array}\right),
$$

where MEintake is the measured intake energy (based on the daily sum of pasture ME and supplement ME calculated from pasture analysis), MEexercise is the measured energy expenditure due to exercise (based on measured daily distance walked and $2 \mathrm{MJ}$ of $\mathrm{ME}$ $\mathrm{km}^{-1}$ walked on flat land to the milking platform and 
$3 \mathrm{MJ}$ of $\mathrm{ME} \mathrm{km} \mathrm{km}^{-1}$ walking rolling terrain), MEmain is the energy requirement for maintenance, MEmilk is the energy requirement for milk, MEbcs is the energy requirement for change in BCS, and MEbcnf is the energy requirement for change in body content nonfat. An assessment of pasture DMI was performed for each treatment during the experimental period using the rising plate meter (Farmworks, Palmerston North, New Zealand) technique. This involved a daily assessment of pre- and post-grazing pasture mass. The average DMI of pasture consumed per animal was calculated as the difference between the pre- and postgrazing pasture mass, multiplied by the area offered (meters), and then divided by the number of cows in the group. Pasture samples were collected by taking a minimum of 10 cuts to $5 \mathrm{~cm}$ above the ground at random intervals across the paddock and submitted for analysis every 2 wk (Hills Laboratory, Hamilton, New Zealand) to determine pasture ME intake. The equations are

$$
\begin{aligned}
& \text { MEmain }_{t}=\frac{0.53}{k_{m}}\left(\frac{L W T_{t}}{1.08}\right)^{0.67} \\
& \text { MEmilk }_{t}=\frac{1}{k_{l}}\left(34.8 \text { Fat }_{t}+22.3 \text { Prot }_{t}+19.9 \text { Lact }_{t}-0.108 \text { Vol }_{t}\right) \\
& B C F_{t}=\frac{1}{100}\left(-1.1043+1.7541 \times B C S_{t}\right) \times\left(0.8117 \times L W T_{t}\right) \\
& M E b c f_{t}=\frac{E_{f a t}}{k_{g}}\left(B C F_{t}-B C F_{t-1}\right) \\
& B C N F_{t}=0.8117 \times L W T_{t}-B C F_{t} \\
& M E b c n f_{t}=\frac{E_{n f a t}}{k_{g}}\left(B C N F_{t}-B C N F_{t-1}\right)
\end{aligned}
$$

where $t$ is time (d), $B C F$ denotes the body content of fat $(\mathrm{kg}), B C N F$ denotes the body content nonfat $(\mathrm{kg})$, $L W T$ is liveweight ( $\mathrm{kg})$, empty BW is assumed to be 81.17\% of liveweight (Gregory et al., 1998), Fat, Prot, Lact, and $\mathrm{Vol}$ are the total daily fat, protein, lactose, and volume yields $(\mathrm{kg})$, respectively, the heat of combustion for body fat is $E_{\text {fat }}=39.33 \mathrm{MJ} \cdot \mathrm{kg}^{-1}$, the heat of combustion for body nonfat is $E_{n f a t}=21.83 \mathrm{MJ} \cdot \mathrm{kg}^{-1}$, the efficiency of energy for growth is $k_{g}(=0.55)$, the efficiency of energy for maintenance is $k_{m}(=0.678)$, and the efficiency of energy for lactation is $k_{l}(=0.6$; AFRC, 1993). Intake, exercise (walking distances), and milk yield (in-line milk meters) were measured daily. Milk composition was measured weekly, and LWT and BCS were measured weekly by a single observer, and these were interpolated with a shape-preserving piecewise cubic interpolation to obtain daily estimates.

\section{Model-Fitting Procedure}

The model equations (Eq. [1-5]) were fitted to the multi-response data (progesterone and $\log _{10}$ embryo length) using nonlinear regression (Bates and Watts, 2007). Models were first calibrated to literature data and then validated using our data. The variances of the deviations in measurements within response variables were assumed constant, possibly dependent, and allowed for the variances in measurement deviations to be different between response variables. Embryo length measurements were log-transformed for model fitting. A weighted least squares procedure was used when standard errors on measurements were available. Identifiability analyses were performed to ensure that the estimated model parameters were unique.

Differential equations were solved using ode15s in MATLAB (The MathWorks, Natick, MA). Markov chain Monte Carlo (MCMC) was used to determine the standard errors in the model parameters (Gilks et al., 1996). A likelihood ratio test was used to compare nested models (Bates and Watts, 2007).

\section{Embryo Analysis}

Trophectoderm expression of 9 genes temporally expressed in embryonic development was examined by quantitative reverse transcription (RT) PCR. These were trophectoderm cell-specific: IFNT, trophoblast Kunitz domain protein 1 (TKDP1), dickkopf 1 (DKK1), pregnancy-associated glycoprotein 11 (PAG11); or trophoblast binucleate cell specific: bovine placental lactogen $(C S H 2$, previously $b P L)$, prolactin-related protein 1 (PRP1), and PAG9. Podoplanin (PDPN), identified from an in-house embryonic RNASeq analysis as upregulated in Day 14 embryos, was quantified, as well as prostaglandin $\mathrm{G} / \mathrm{H}$ synthase 2 (PTGS2), whose enriched expression in blastocysts has been correlated with pregnancy success (Ghanem et al., 2011).

Reverse transcription of RNA extracted from the TE stored in TRIzol was as previously described (Smith et al., 2007). Briefly, the RNA was extracted using chloroform-isoproanol from stored samples with MS2 RNA (Roche, Mannheim, Germany) and linear acrylamide (Ambion, Austin, TX) carriers followed by removal of any remaining DNA with RNase-free DNase1 (Invitrogen, Carlsbad, CA). Reverse transcription was performed with oligo $\mathrm{dT}_{20}$ anchored primer, RNase OUT inhibitor, and Superscript III (Invitrogen). An RT negative control was included.

Quantification of RNA was conducted via SYBR Green-based RT-PCR using a Corbett Rotor-Gene 600 machine with $10-\mu \mathrm{L}$ reactions containing $5 \mu \mathrm{L}$ of TaKaRa Sybr Premix Ex Taq mix (Takara Bio Inc., Otsu, 
Japan), $0.1 \mu M$ each primer, and $2 \mu \mathrm{L}$ of template (Ledgard et al., 2009). The thermal program involved a 1-min activation incubation at $95^{\circ} \mathrm{C}$ followed by 40 cycles of $95^{\circ} \mathrm{C}$ for $10 \mathrm{~s}$, an annealing temperature of $60^{\circ} \mathrm{C}$ for $15 \mathrm{~s}$, and extension at $60^{\circ} \mathrm{C}$ for $20 \mathrm{~s}$, with a ramp speed of $20^{\circ} \mathrm{C} \mathrm{s}^{-1}$. A no-template control, an RTnegative control, and an RT-positive control were included in each run. The PCR products were sequenced (University of Waikato, Hamilton, New Zealand) to verify correct identity (Table 1 ). Values are expressed as the relative copy number (RCN) normalized against the geometric mean of 3 internal housekeeping controls (GAPDH, RPL19, and UBE2K) for each sample (Wilkening and Bader, 2004).

\section{Statistical Analysis}

The Akaike information criterion (AIC) was used to determine the best model to describe embryo survival. The AIC is an objective method for selection of the best model for data analysis (Burnham and Anderson, 2002) and has been used to compare different embryo survival models to data (Roberts et al., 2010; Shorten et al., 2013). Model parameters and their standard errors were estimated using maximum likelihood (Pawitan, 2001). The data were also analyzed using generalized linear models and generalized linear mixed models with binomial distribution and logit link. Model residuals were analyzed for homoscedasticity and normality. Calculations were performed in $\mathrm{R}$ and Matlab (The Mathworks).
Relationships between TE length, ED length/area, and gene expression were determined on log-transformed data. Multivariate linear regression was also used to investigate the effect of progesterone, EB, and embryo transfer size on the gene expression, ED size, and TE length on Day 15 embryos. The error variance covariance matrix was assumed to be unstructured (correlated and heteroscedastic). The model represents a continuous response vector ( $d$-dimensional) as a linear combination of predictors $(K-1)$ and a multivariate normal $(M V N)$-distributed error vector. For the $i$ th observation $\left(\mathbf{y}_{i}\right)$, given the design matrix $\mathbf{X}_{i}(\mathrm{~d} \times \mathrm{K})$ and the vector of regression coefficients $\boldsymbol{\beta}(\mathrm{K} \times 1)$, the multivariate linear regression model for the response vector $(\mathrm{d} \times 1)$ is

$$
\mathbf{y}_{i}=\mathbf{X}_{i} \boldsymbol{\beta}+\boldsymbol{\varepsilon}_{i}, \quad \boldsymbol{\varepsilon}_{i} \sim \operatorname{MVN}_{d}(\mathbf{0}, \boldsymbol{\Sigma}),
$$

where the errors $\left(\varepsilon_{i}\right)$ are assumed independent between observations and multivariate normal distributed with variance-covariance matrix $\boldsymbol{\Sigma}$ (Rencher 2002). The regression coefficients and error variance-covariance matrix were estimated using maximum likelihood. Standard errors were calculated according to the inverse of the observed Fisher information matrix. An expectation/conditional maximization algorithm was used to impute missing response values for gene expression $(4$ out of 296 gene expression measurements over the 6 major genes of interest) and ED size ( $\mathrm{n}=4$ embryos). Model residuals were tested to be independent, with a multivariate normal distribution.

Table 1. Quantitative real-time reverse transcription-PCR primer sequences

\begin{tabular}{|c|c|c|}
\hline Gene symbol & Accession no. & Primer sequence $5^{\prime}$ to $3^{\prime}$ (forward, reverse) \\
\hline$\overline{\mathrm{CSH} 2}$ & J02840 & $\begin{array}{l}\text { GTTCATCAACAGCTGCCACA } \\
\text { GGATGGATCATCACTAACCA }\end{array}$ \\
\hline$D K K 1$ & XM_580572 & $\begin{array}{l}\text { CAGTGTGGCACTTACCTGTA } \\
\text { GGGGGAAGGGTTTTACAT }\end{array}$ \\
\hline$G A P D H$ & BC102589 & $\begin{array}{l}\text { CTCCCAACGTGTCTGTTGTG } \\
\text { TGAGCTTGACAAAGTGGTCG }\end{array}$ \\
\hline$I F N T$ & NM_001015511.3 & $\begin{array}{l}\text { GCTATCTCTGTGCTCCATGAGATG } \\
\text { AGTGAGTTCAGATCTCCACCCATC }\end{array}$ \\
\hline PAG9 & BC123608 & $\begin{array}{l}\text { TCCTTTTGTACCATGCCAGC } \\
\text { TGCCCTCCTGCTTGTTTTTC }\end{array}$ \\
\hline PAG11 & NM_176623.2 & $\begin{array}{l}\text { CCCAAACCAAAAGCTGGCTAATAA } \\
\text { ATCGATGCCATTGATGGTGAA }\end{array}$ \\
\hline$P D P N$ & NM_001033120.1 & $\begin{array}{l}\text { TGGCTACGGAGCTTTTTCAT } \\
\text { CACACCCAGGGTTGTTTTCT }\end{array}$ \\
\hline$P R P 1$ & NM174443 & $\begin{array}{l}\text { TGGTCATCAAAATGTACGTGGT } \\
\text { AGTAGACAAAGCCCAGGAACAG }\end{array}$ \\
\hline PTGS2 & AF031698 & $\begin{array}{l}\text { TAGAATCCTGTTCGGGTACAGTCAC } \\
\text { TCCTTGCTGTTCCCATCCATGT }\end{array}$ \\
\hline RPL19 & XM_002695953.3 & $\begin{array}{l}\text { CCAGTGTCCTTCGCTGTGGCA } \\
\text { GGCATCGAGCCCGGGAATGG }\end{array}$ \\
\hline TKDP1 & NM_205776.1 & $\begin{array}{l}\text { CATACACTAGAGGAATTCCCAA } \\
\text { TGCTGAGTATTCAATCTTGAGTG }\end{array}$ \\
\hline UBE2K & BC142324 & $\begin{array}{l}\text { CAGCGAATCAAGCGGGAGTT } \\
\text { GCCCCTGTGACGGAACTAA }\end{array}$ \\
\hline
\end{tabular}




\section{RESULTS AND DISCUSSION}

\section{Embryo Recoveries}

One hundred sixty-seven embryos were recovered from 55 of 66 flushing events completed at Day 15 of gestation, and the remaining 11 flushings were considered nonpregnant. From 13 of these flushings, only a single embryo was recovered from the bulk transfer of 4 to 6 blastocysts $8 \mathrm{~d}$ earlier. However, multiple embryos of very similar lengths were recovered from 19 flushings, and multiple embryos of varying lengths were recovered from 23 flushings. The length of intact conceptuses was between 0.34 and $170 \mathrm{~mm}$; however, in some cases, precise measurement of TE length was not possible because of conceptus damage during the recovery process $(\mathrm{n}=15)$. The average length of recovered embryos was $1.18 \log _{10} \mathrm{~mm}$, with a standard deviation of $0.68 \log _{10}$ $\mathrm{mm}$ (mean of $52 \mathrm{~mm}$ ). Based on developmental stage, the predicted average number of cells in the transferred embryos was $2.19 \log _{10}$ cells with a standard deviation of $0.09 \log _{10}$ cells (mean of 158 cells).

\section{Modeling Embryo Growth}

Calibration of the Progesterone Model to Literature Data. The progesterone model (Eq. [1]) predicted progesterone measured daily on Day 1 to 14 by other researchers (Tsai and Wiltbank, 1998; Mann et al., 2006; Clemente et al., 2009; Forde et al., 2011) with good accuracy $\left(\mathrm{R}^{2}=0.99\right)$. The progesterone model also provided a good prediction of progesterone concentration on Day 7 and over Days 2, 5, 7 and 15 combined $\left(\mathrm{R}^{2}=0.99\right)$. This is demonstrated for the Tsai and Wiltbank, (1998) progesterone dynamics in that 4 progesterone measurements (on Days 2, 5, 7, and 15) can be utilized by the model (Eq. [1]) to provide a good prediction of progesterone on Days 1 to 15 (Figure 1). We also found that the estimated model parameters for progesterone dynamics (Tsai and Wiltbank, 1998; Mann et al., 2006; Clemente et al., 2009; Forde et al., 2011) based on a subset of the progesterone data (Days $2,5,7$, and 15) were not significantly different from the estimated model parameters using the full progesterone data (Days 1-14).

Calibration of the Embryo Growth Model to Literature Data. The embryo growth (EG) model (Eq. [1-5]) was fitted to a mix of data from different laboratories and countries regarding the effect of circulating progesterone on embryo length at Days 14 to 16 (Mann et al., 2006; Clemente et al., 2009; Forde et al., 2011; O'Hara et al., 2016), providing a description of embryo growth in an average cow. Over the 8 experiments in these studies, the ability of the EG model to

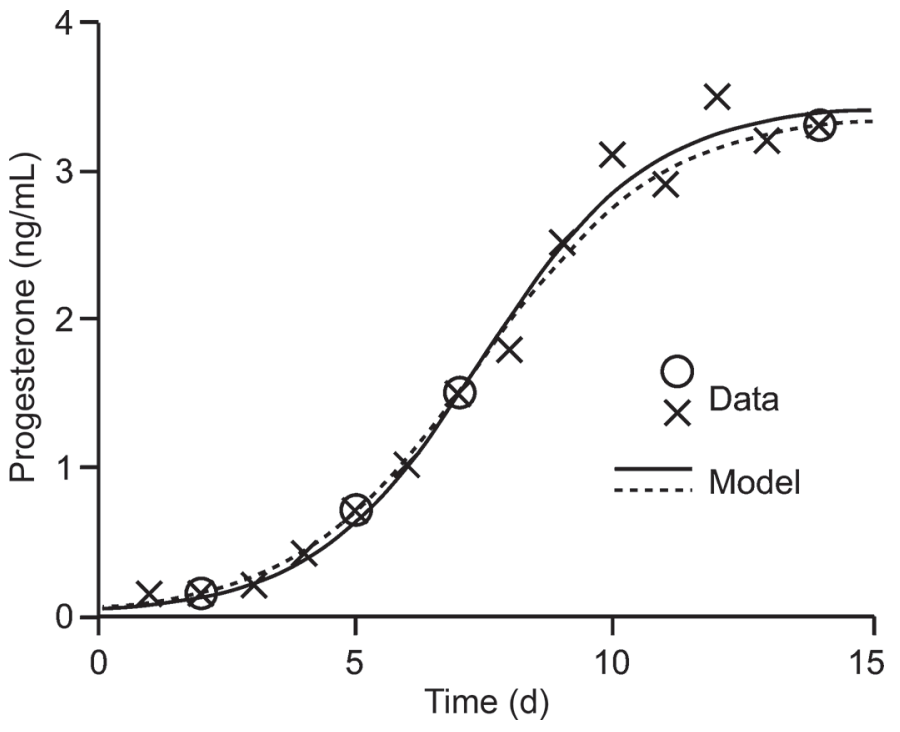

Figure 1. The estimated model progesterone dynamics based on the full progesterone data (Day 1-14; $\times$, solid line) or based on a subset of the progesterone data (Days 2, 5,7 , and $15 ; \bigcirc$, dotted line) using data from Tsai and Wiltbank (1998).

predict embryo length is shown in Figure $2 \mathrm{~A}\left[\mathrm{R}^{2}=0.73\right.$ $(0.14,0.95)$, where the values in parentheses denote a $95 \% \mathrm{CI} ; \mathrm{n}=8]$. The estimated model parameters are $a=0.018 \pm 0.002 \mathrm{ng}^{-1} \cdot \mathrm{mL}, b=4.75 \pm 0.16 \mathrm{~d}$, and $n$ $=0.42 \pm 0.02$ (assuming $g=1$ because the data does not allow for $g$ to be estimated independently and $g$ $=1$ corresponds to equal cell dividing time pre- and post-blastocyst hatching). The EG model was also calibrated on a separate data set (O'Hara et al., 2014a,b) that displayed improved embryo growth characteristics (independent of treatments) to better ascertain the underlying reasons for this improved growth. The ability of the model to predict embryo length in these further 8 experiments is shown in Figure $2 \mathrm{~B}\left[\mathrm{R}^{2}=0.87(0.43\right.$, $0.98) ; \mathrm{n}=8]$. The estimated EG model parameters are $a=0.047 \pm 0.006 \mathrm{ng}^{-1} \cdot \mathrm{mL}, b=5.24 \pm 0.29 \mathrm{~d}$, and $n$ $=0.46 \pm 0.03$ (assuming $g=1$ ). The embryo growth parameter $a$ was significantly greater in O'Hara et al. $(2014 a, b)$ than the mix of data in the earlier experiments (Figure 2A, $P<0.001$ ), which is consistent with altered embryo growth in the group of cows studied by O'Hara et al. (2014a,b). Parameters $b$ and $n$ were not significantly different between the 2 data sets. The ability of the EG model to predict embryo length in all 16 experiments combined (Figure $2 \mathrm{~A}, \mathrm{~B}$ ) is $\mathrm{R}^{2}=0.81$ $(0.53,0.93)$.

Validation of the EG Model with our Data. The EG model was fitted to the data for each cow regarding the effect of circulating progesterone and the developmental morphology of the transferred blastocyst on the average recovered embryo length on Day 
15. We observed a tendency $(P=0.1)$ for decreased growth as a larger number of embryos $(\mathrm{n}=4,5,6)$ were transferred. Embryo size on Day 15 was dependent on progesterone $(P<0.01)$ and developmental stage on Day $7(P<0.05)$. The ability of the model to predict the average recovered embryo length is shown in Figure $2 \mathrm{C}\left[\mathrm{R}^{2}=0.52(0.32,0.69) ; \mathrm{n}=55\right]$. The estimated model parameters were $a=0.0165 \pm 0.001 \mathrm{ng}^{-1} \cdot \mathrm{mL}$ and $n=0.466 \pm 0.02$ (assuming $g=1$ and $b=4.75$ d). The estimated embryo growth parameters $(a, n)$ were not significantly different from those for the mix of data (Figure 2A); however, the embryo growth parameter $a$ was significantly greater in the O'Hara et al. (2014a,b) data (Figure 2B). A reduced model of only the effect of progesterone on embryo length on Day 15 (based on average transferred blastocyst size) explained a smaller proportion of the variance in embryo length
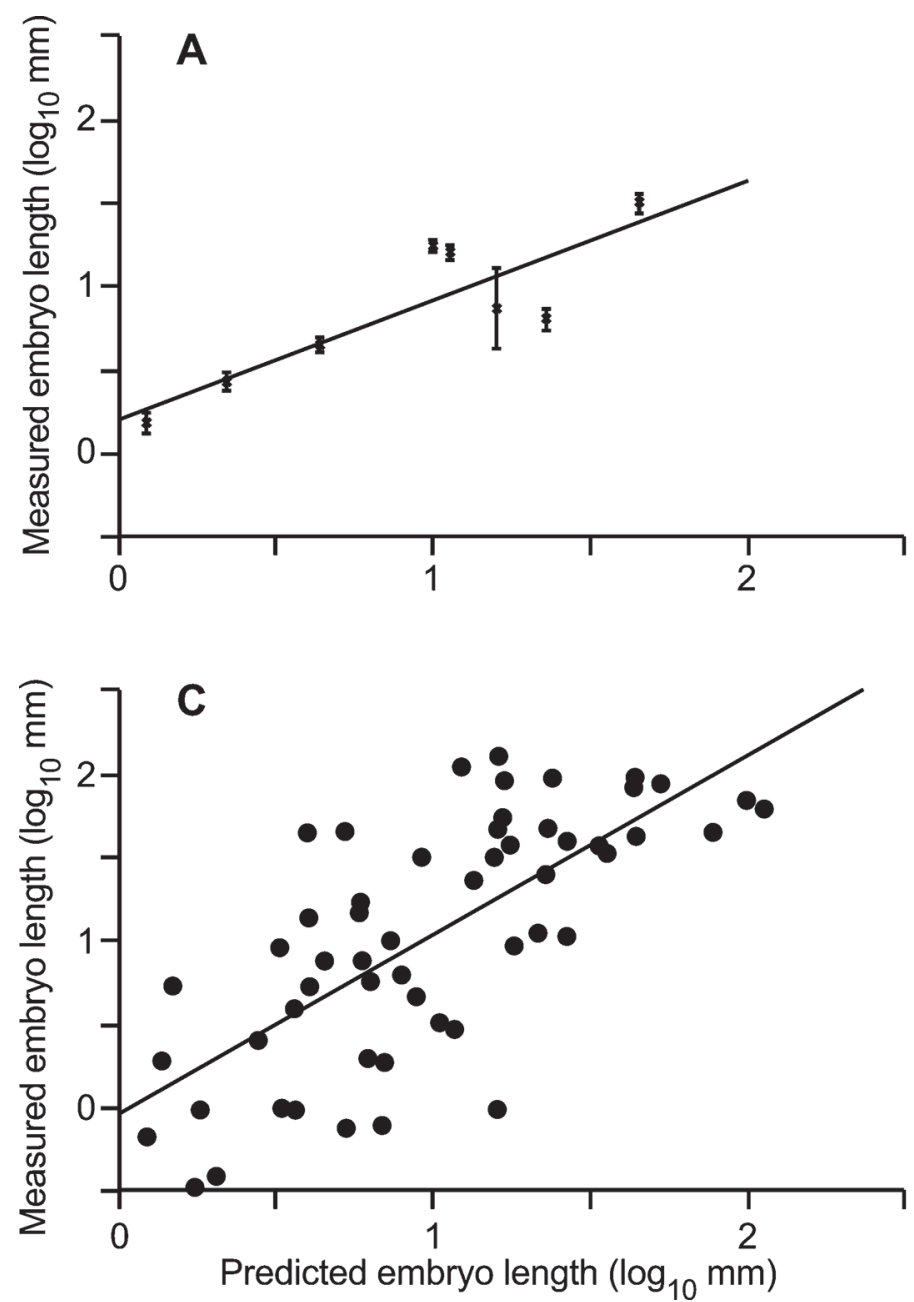

$\left(\mathrm{R}^{2}=0.47\right)$. The EG model was also able to predict the length of individual embryos for cows with full recovery of all transferred embryos (Figure 2D; $\mathrm{R}^{2}=0.47, \mathrm{n}=$ 43), assuming that the order of embryos (based on size) is not likely to change within a cow between Day 7 and Day 15, although stochastic effects may change this order in a particular cow. Such stochastic effects in the growth process (based on the difference in the variance estimates) can be modeled using stochastic differential equations similar to those developed for modeling stochastic growth in microbiology applications (Shorten et al., 2006). However, the standard deviation in the measured embryo length on Day $15\left(0.52 \pm 0.06 \log _{10}\right.$ $\mathrm{mm}$ ) was not significantly different from that in the predicted embryo length on Day $15\left(0.43 \pm 0.05 \log _{10}\right.$ $\mathrm{mm})$ based on the deterministic EG model and Day 7 embryo size (Figure 2D; $P=0.2$ ). This indicates that
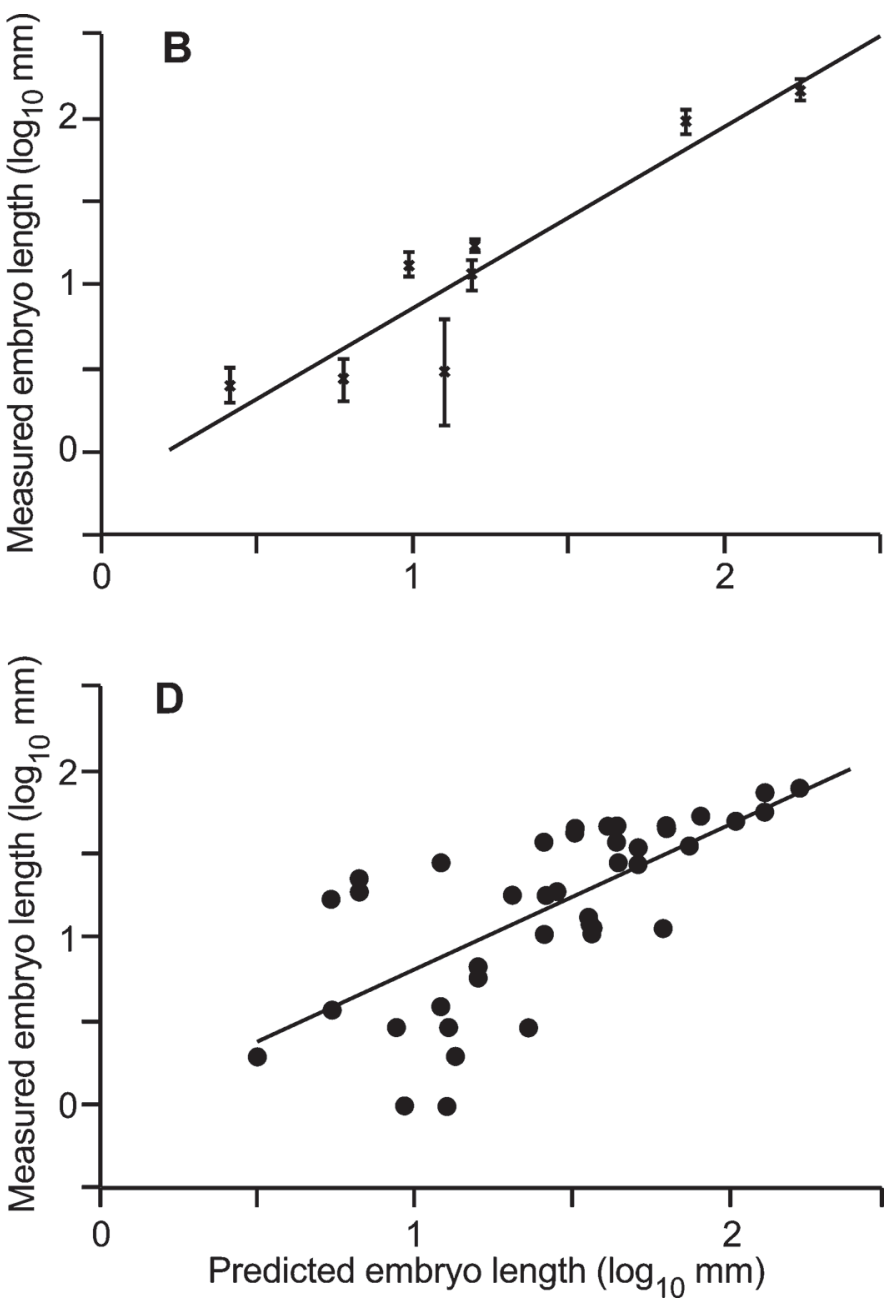

Figure 2. The ability of the embryo growth model (Equations [1-5]) to predict the effect of circulating progesterone (A) on embryo length on Day 14-16 ( $\left.\mathrm{R}^{2}=0.73\right)$ using data from Mann et al. (2006), Clemente et al. (2009), Forde et al. (2011), and O'Hara et al. (2016); (B) on embryo length on Day 14-16 ( $\left.\mathrm{R}^{2}=0.87\right)$ using data from O'Hara et al. (2014a,b); (C) the size of transferred embryo on average recovered embryo length on Day $15\left(\mathrm{R}^{2}=0.52 ; \mathrm{n}=55\right.$ cows); and $(\mathrm{D})$ the size of transferred embryo on the length of individual embryos on Day $15\left(\mathrm{R}^{2}=0.47\right.$; $\mathrm{n}=43$ embryos). Error bars denote SEM. 
stochastic effects in growth that change the order of embryo size within a cow are relatively small, as large stochastic growth effects would generate a significantly larger standard deviation in measured embryo length on Day 15. Thus, modeling using stochastic differential equations was not necessary.

Others have shown a clear relationship between the kinetics of development of early bovine embryos to first cleavage after insemination and developmental competence (Holm et al., 1998, 2002; Lonergan et al., 1999). However, we found that although Day 15 embryo size is dependent on the specific morphological stage (indicative of cell number or size) of the Day 7 blastocyst when it was transferred, progesterone is a more important factor than transferred embryo size on subsequent growth. The fact that our EG model was able to predict embryo lengths in cases where all embryo had been recovered, on the stated assumption that the order of embryos based on size is not likely to change, suggests that this assumption may be correct.

The Role of EB on Embryo Growth in our Data. We found no effect of average EB from $40 \mathrm{~d}$ before transfer to recovery on progesterone on Day 2 $(P=0.5)$, Day $7(P=0.9)$, or Day $15(P=0.6)$. Lower average energy balance over the $40 \mathrm{~d}$ before transfer was associated with reduced embryo growth to Day $15\left[\beta_{E B}=0.0043 \pm 0.0021 \log _{10} \mathrm{~mm}\left(\mathrm{MJ} \cdot \mathrm{d}^{-1}\right)^{-1} ; P<\right.$ $0.05]$ and this energy balance effect is independent of progesterone (the EB effect remains when progesterone is included as a covariate in the model; i.e., it cannot be explained by progesterone). Lower EB over the period from transfer to recovery was also associated with reduced embryo growth to Day $15\left[\beta_{E B}=0.003 \pm 0.0014\right.$ $\left.\log _{10} \mathrm{~mm}\left(\mathrm{MJ} \cdot \mathrm{d}^{-1}\right)^{-1} ; P<0.05\right]$ and this EB effect is independent of progesterone. Average EB from $40 \mathrm{~d}$ before transfer is moderately correlated with average EB from transfer to recovery $(\mathrm{R}=0.5)$ and this makes it difficult to distinguish between EB effects before and after embryo transfer. The effect of average EB $\left(\mathrm{MJ} \cdot \mathrm{d}^{-1}\right)$ before transfer on embryo growth to Day 15 is not significantly different from the effect of average EB after transfer on embryo growth to Day $15(P=$ $0.6)$. Furthermore, the effect of cumulative EB (MJ) before transfer on embryo growth to Day 15 was not significantly different from the effect of cumulative EB (MJ) after transfer on embryo growth to Day $15(P=$ $0.4)$. This observation is a component of the association between lower EB and reduced pregnancy rate (Roche et al., 2011). Our findings are complementary to the association between negative energy balance and impaired follicular development (Beam and Butler, 1997) and highlight that both embryonic and uterine factors are regulated by EB. The intrinsic capability of the blastocyst is an initial driver of early pregnancy loss when development blocks or is slow at the blastocyst stage; otherwise, the uterine environment, driven by progesterone and $\mathrm{EB}$, is a more important component in the stimulation of embryonic growth.

\section{Embryo Survival}

Embryo Survival Model Selection for Inference Based on our Data. The AIC provides an objective criterion for selection of the best model for data analysis. The best model was Eq. [10] $(\mathrm{AIC}=112.917)$, followed by Eq. [9] $(\mathrm{AIC}=118.295)$, Eq. [7] $(\mathrm{AIC}=$ 118.477), Eq. [8] (AIC = 125.366), and Eq. [6] $(\mathrm{AIC}=$ 140.221). This indicates that embryo survival can be considered by a model in which cow receptiveness is a Bernoulli random variable, embryo viability is a binomial random variable, and the embryo survival probability is progesterone-dependent and variable between cows. We therefore used Eq. [10] for data inference in this section.

Embryo Survival for our Data (All Cows). The effect of number of embryos transferred $(4,5$, or 6 ) on embryo survival probability ( $p$ in Eq. [10]) was not significant. This is consistent with the findings of Berg et al. (2010), who only observed an effect of number of transferred embryos on embryo survival over this period when $>20$ embryos were transferred. The estimated survival probability for an individual embryo is $p=0.51 \pm 0.04$ (Eq. [10]). Day 15 embryos $<2 \mathrm{~mm}$ have been successfully retransferred resulting in a calf (Betteridge et al., 1980), suggesting that our estimates of the embryo survival probability of an individual embryo $(p=0.51 \pm 0.04)$ are not significantly biased. There was a significant effect of progesterone on Day 7 on embryo survival probability from Day 7 to 15 [Eq. [10], Figure 3; $\beta_{p, 1}=0.054 \pm 0.017\left(\mathrm{ng} \cdot \mathrm{mL}^{-1}\right)^{-1} ; P<$ 0.01]. There was no quadratic effect of progesterone on embryo survival, although embryo survival tended to be lower for high progesterone on Day $7(P=0.1$, Eq. [10]). This trend is consistent with Stronge et al. (2005), who observed a significant negative quadratic relationship between milk progesterone on Day 7 and embryo survival. Progesterone on Day $7.8 \pm 1.5$ was the best predictor of embryo survival (based on Eq. [1] and ]10]). Given the $\sim 2$-d delay between circulating progesterone and progesterone-induced changes in the uterine environment in which the embryo is developing (Clemente et al., 2009), this suggests that progesteronedependent effects on embryo survival are greatest on Day $9.8 \pm 1.5$. We detected no effect of developmental stage of the transferred embryo on embryo survival probability to Day 15 (Eq. 10). There was also no effect of average EB from $40 \mathrm{~d}$ before transfer to recovery on embryo survival to Day 15: $\beta_{E B}=0.00064 \pm 0.0011$ 
$\left(\mathrm{MJ} \cdot \mathrm{d}^{-1}\right)^{-1} ; P=0.6$, Eq. [10]. The estimated standard deviation in embryo survival between cows is at least $\sigma_{C}=0.22 \pm 0.04$ (assuming $\sigma_{E}<0.289 ; P<0.01$ ). This is consistent with the between-animal variance in embryo/fetal survival in sheep (Shorten et al., 2013).

Embryo Survival for our Data (Cows with Partial Embryo Losses). A second analysis was based only on cows with partial embryo losses (i.e., cows with no recovered embryos were removed). Cows with complete embryo loss represent a subpopulation of cows where embryo survival is likely driven by maternal factors. An analysis of the cows with partial embryo losses represents a subpopulation where embryo factors dominate embryo survival (i.e., $r=1$ ). For the partial embryo losses data set, there was no significant effect of Day 7 progesterone on embryo survival $\left(\beta_{p, 1}=0.015 \pm\right.$ $0.015 ; P=0.3)$ although there was a significant effect of EB from transfer to recovery on embryo survival $\left[\beta_{E B}\right.$ $\left.=0.0015 \pm 0.00056\left(\mathrm{MJ} \cdot \mathrm{d}^{-1}\right)^{-1} ; P=0.01\right]$. Although there was an effect of EB from $40 \mathrm{~d}$ before transfer on embryo survival $(P=0.05)$, this effect is only due to its covariance with EB from transfer to recovery. The effect of EB from transfer to recovery is independent of EB $40 \mathrm{~d}$ before transfer $(P=0.04)$. This suggests that progesterone effects on embryo survival are mediated through maternal factors, which is consistent with the observation that the effects of progesterone on bovine embryo growth are through the maternal environment (Clemente et al., 2009), whereas EB effects on embryo survival are largely mediated by direct effects on the embryo and the maternal environment.

\section{Trophectoderm Gene Expression}

The TE from the largest embryos recovered from each uterine tract (covering lengths from 0.34 to $170 \mathrm{~mm}$ ) and uterine environments under a range of progesterone influence (Day 7 progesterone: $1.07-11.71 \mathrm{ng} \cdot \mathrm{mL}^{-1}$ ) were processed for quantification by RT-PCR. The largest embryos recovered were used to represent the maximum uterine ability to stimulate growth and to reduce the effect of the variability in the size of transferred embryos (i.e., embryos between cows are more comparable). Of these, $(\mathrm{n}=49 ; 4$ embryos with incomplete lengths recovered were omitted) the length of the embryo correlated positively with increased expression of IFNT, TKDP1, PAG11, PTGS2, and DKK1 ( $\mathrm{r}=$ $0.79,0.76,0.78,0.63$, and 0.56 , respectively; $P<0.001$ ) and correlated negatively with $P D P N(\mathrm{r}=-0.74 ; P$ $<0.001$; Figure 4). No expression of DKK1 was detected in the 5 embryos $1 \mathrm{~mm}$ or less (a sixth produced insufficient cDNA to test for these genes). Trophectoderm longer than $19 \mathrm{~mm}(\mathrm{n}=31)$ were examined for

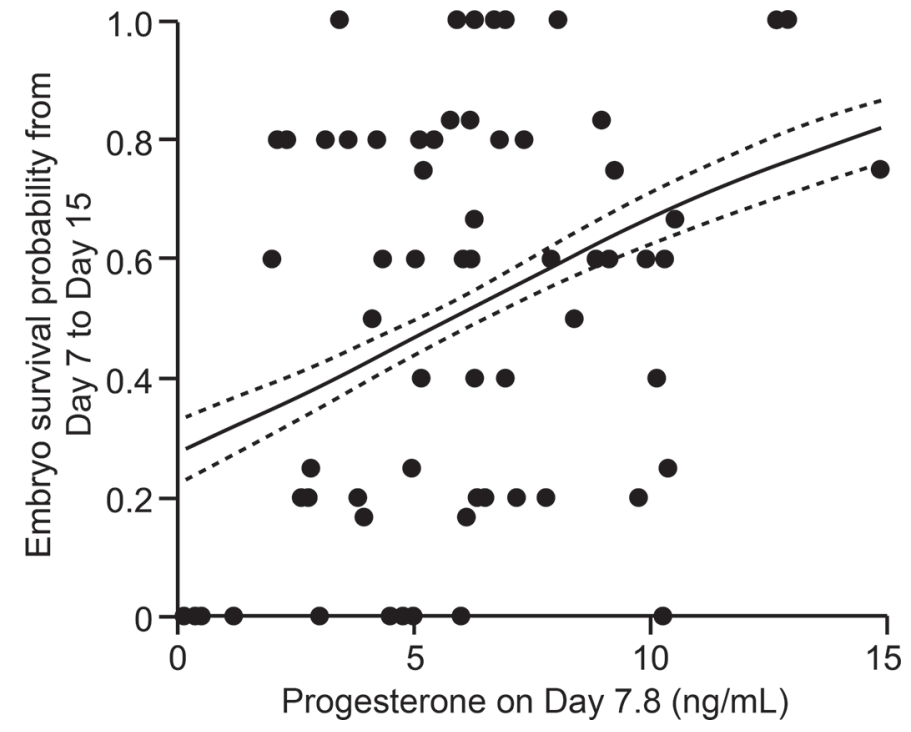

Figure 3. The effect of progesterone on Day 7.8 on the probability of embryo survival from Day 7 to 15 . The solid line denotes the model fit and the dotted lines denote standard errors $(P<0.01)$.

expression of binucleate-specific genes CSH2, PRP1, and PAG9 but no expression was detected even in the longest trophectoderm (170 mm; data not shown). Embryo length was well explained by $P D P N, D K K 1$, and PAG11 $\left(\mathrm{R}^{2}=0.77\right)$. The effects of the remaining genes on Day 15 embryo length can be explained by their covariance with $P D P N, D K K 1$, and PAG11.

Gene expression in the TE tissue of the representative embryos showed IFNT, TKDP1, PAG11, PTGS2, and $D K K 1 \mathrm{mRNA}$ levels were positively correlated with conceptus length. Expression of trophectoderm-specific IFNT and TKDP1 is known to increase in early gestation as length increases (Smith et al., 2010) as is expression of PAG11, which is most highly expressed at Day 17 of gestation and is present in both the mononucleated and binucleated cells of the trophectoderm (Green et al., 2000). Another member of this large family, PAG9, is expressed exclusively in binucleate cells and has been detected in some Day 17 conceptuses (Thompson et al., 2012). Even though several of the embryos in this trial reached a length equivalent to that of embryos previously recovered on gestational Day 17 (Ledgard et al., 2011), none reached the developmental stage of TE binucleate cell formation, because mRNA for PAG9 and the other binucleate cell-specific markers $C S H 2$ and PRP1 (Patel et al., 2004) was not detected. Enhanced PTGS2 expression is proposed as a blastocyst stage marker for potential pregnancy success (Ghanem et al., 2011) and its positive correlation with Day 15 embryo length, as shown in the current study, suggests that it could be used as an indicator of embryonic growth. The 
correlation between $D K K 1$ expression was more moderate, with no expression in the smallest, and probably undeveloped, embryos $(<1 \mathrm{~mm})$. We have shown here that $P D P N$, which is expressed in the mesothelium of secondary human yolk sac (Nogales and Dulcey, 2012), was negatively correlated with TE length. This likely reflects the change in the proportion of mesothelial to trophectoderm cells as the conceptus elongates. It appears that TE expression of many genes is closely linked to the developmental length of the embryo.
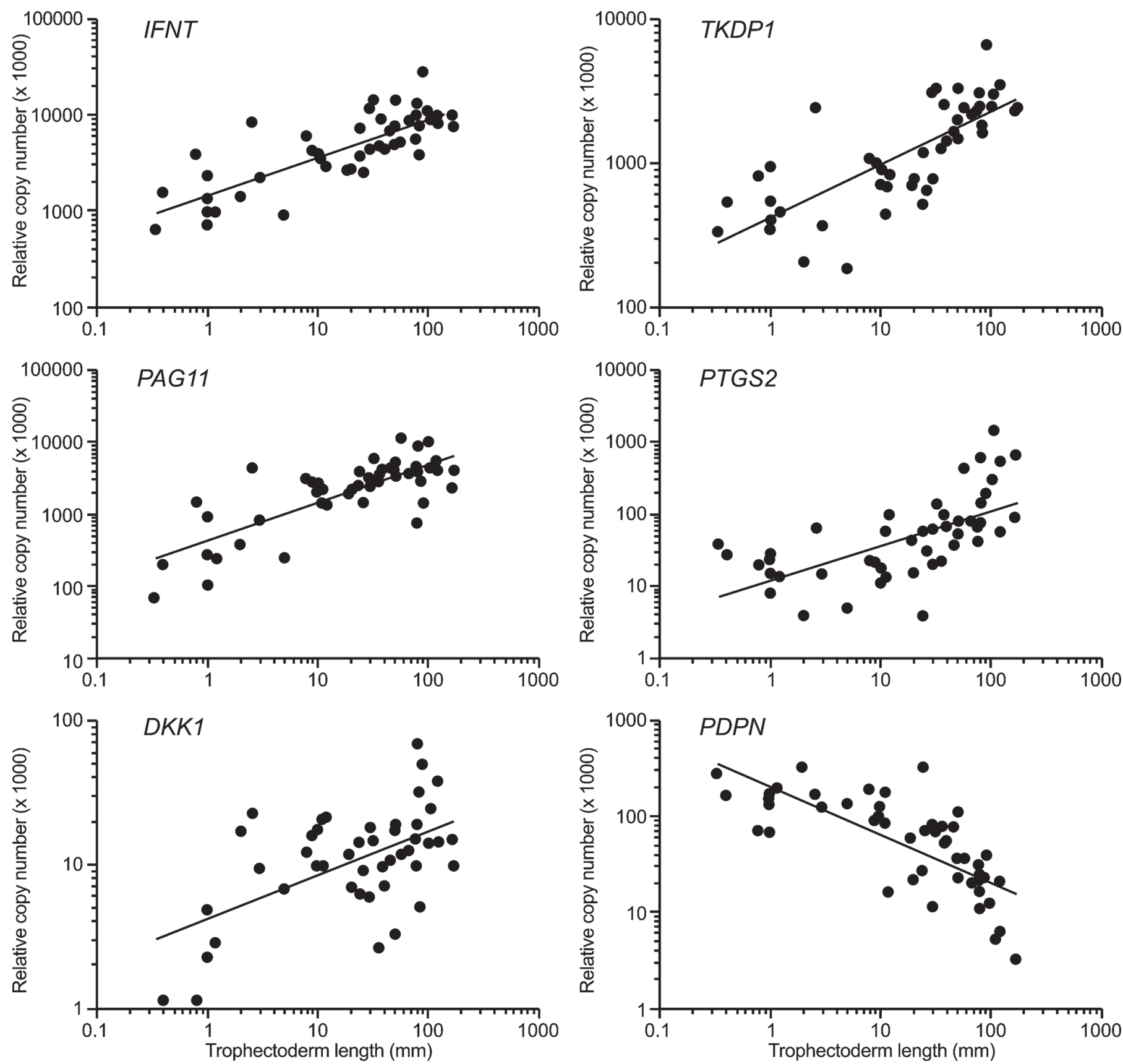

Figure 4. Comparison between trophectoderm (TE) length $(\mathrm{mm})$ of the largest embryo recovered from each flushing of cows $(\mathrm{n}=49,4$ fragmented TE omitted) $8 \mathrm{~d}$ after bulk transfer of Day 7 blastocysts and gene expression of IFNT (interferon tau); TKDP1 (trophoblast Kunitz domain protein 1); PAG11 (pregnancy-associated glycoprotein 11); PTGS2 (prostaglandin G/H synthase 2); DKK1 (dickkopf 1); and PDPN (podoplanin) measured by quantitative real-time reverse transcription-PCR. Correlation $\mathrm{r}$-values are $0.79,0.76,0.78,0.63,0.56$, and -0.74 , respectively $(P<0.001)$. Data shows relative copy number of mRNA normalized against the geometric mean of the relative copy number of housekeepers GAPDH, RPL19, and UBE2K. 


\section{Embryonic Disc}

The ED of the largest embryos recovered from each uterine tract were examined by light microscopy and characterized as round, oblong, or pear-shaped ( $\mathrm{n}=$ 25, 15, and 8 respectively; see Supplemental Figure S1; https://doi.org/10.3168/jds.2017-12845; Guillomot et al., 2004). Two embryos had no ED present (TE length 0.34 and $2.6 \mathrm{~mm}$ ) and in 2 embryos, the ED could not be found due to fragmentation of the TE. The area of the ED correlated with TE length $(\mathrm{r}=0.77, P<$ 0.001; Figure 5). Length and width of the ED were highly correlated $(\mathrm{r}=0.88, P<0.001)$. Although TE growth and ED length are correlated (Berg et al., 2010) and ED developmental stages are temporally correlated with ED size (van Leeuwen et al., 2015), whether the ED developmental stages are equally temporally correlated is speculative. We could hypothesize that longer conceptuses have advanced ED development, although this requires further investigation.

\section{Effect of Progesterone, EB, and Embryo Transfer Size on the Day 15 Embryo}

Multivariate linear regression was used to investigate the effect of progesterone on Day 7, EB, and embryo transfer size on gene expression, ED size, and TE length on Day 15 embryo (this choice of predictors and response variables satisfies temporal causality). Because gene expression, ED size, and TE length on Day 15 were highly correlated, multivariate analysis (Eq. [13]) can be used to assess the variables simultaneously

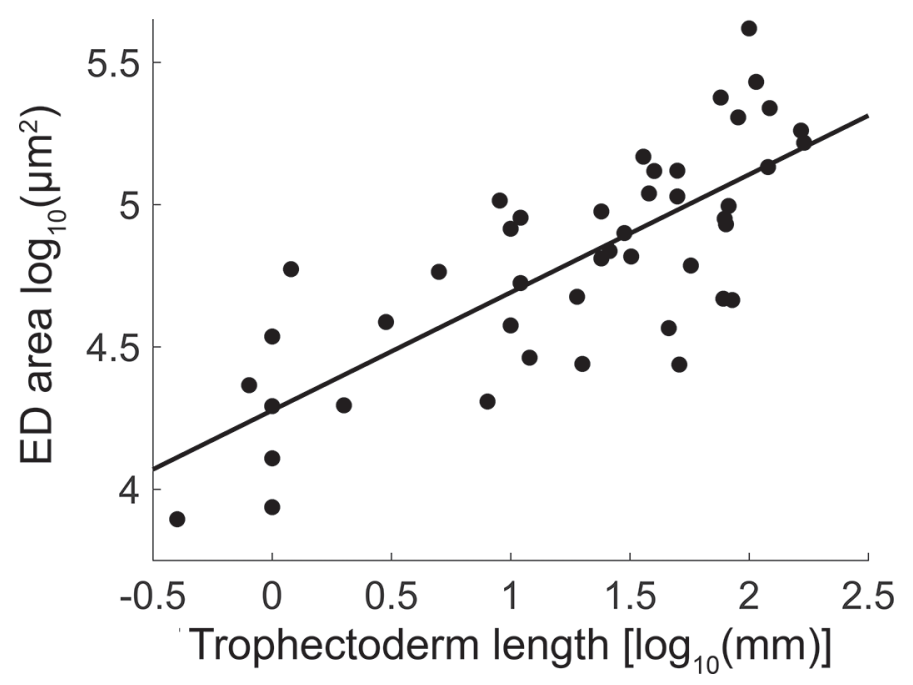

Figure 5. The relationship between trophectoderm lengths $\left(\log _{10}\right.$ $\mathrm{mm}$ ) of the largest embryo recovered from each flushing of cows $8 \mathrm{~d}$ after bulk transfer of Day 7 blastocysts and their embryonic disc (ED) area $\left(\log _{10} \mu \mathrm{m}^{2}\right)$. Correlation r-value is $0.77(\mathrm{n}=45, P<0.001)$. 
and determine the key elements that produced them (Rencher, 2002). The multivariate regression parameter coefficient estimates are listed in Table 2, and the correlation matrix for the error variance-covariance matrix is given in Table 3 . We detected a significant effect of Day 7 progesterone on the expression of all 6 genes, ED size, and TE length on Day 15. This effect was independent of the estimated covariance between the observations on Day 15 (Table 3), suggesting that progesterone acts through multiple pathways to modify these Day 15 observations. In particular, there was a significant effect of progesterone on ED area independent of the effect of progesterone on TE length (i.e., the effect of progesterone on ED area was not due to the covariance between ED area and TE length). Furthermore, progesterone affected gene expression independently of the progesterone effect on TE length. We also detected significant effects of embryo transfer size on TE length and expression of IFNT and PAG11. This highlights that IFNT is not solely dependent on TE length. Effects of embryo transfer size on other genes operate through covariance with these response variables. Energy balance from transfer to recovery had significant effects on $P D P N(P<0.01), T K D P 1(P<0.05)$, and TE length $(P<0.01)$. This provides candidate signaling pathways for the effect of EB on embryo growth to Day 15.

Although IFNT expression was detectable in Day 8 blastocysts (Watson et al., 1992), modeling of the embryo-uterine biological interactions indicates that a time-dependent minimal amount of IFNT protein must be present in the luminal fluid to ensure pregnancy recognition (Shorten et al., 2010). This amount, correlated with embryo length, needs to be determined at the crucial window of IFNT influence. An indication of a threshold has been reported, measured as a difference in IFNT-responsive genes of the peripheral blood mononuclear cells between cows receiving a uterine infusion of recombinant IFNT at 500 compared with $1,000 \mu \mathrm{g} \cdot \mathrm{kg}^{-1}$ of BW (Matsuyama et al., 2012).

\section{Role of Gene Expression on Embryo Survival to Day 15}

We detected significant independent effects of TKDP1, PAG11, and PDPN on embryo survival: $\beta_{\mathrm{TKDP} 1}=-0.39 \pm 0.15\left[\log _{10}\left(\mathrm{RCN} \times 10^{3}\right)\right]^{-1}, P=0.01$; $\beta_{\mathrm{PAG} 11}=0.36 \pm 0.10\left[\log _{10}\left(\mathrm{RCN} \times 10^{3}\right)\right]^{-1}, P=0.01$; and $\beta_{\mathrm{PDPN}}=-0.16 \pm 0.08\left[\log _{10}\left(\mathrm{RCN} \times 10^{3}\right)\right]^{-1}, P=$ 0.04, Eq. [10]. However, we found no significant effect of EB from transfer to recovery on embryo survival from transfer to recovery when effects due to TKDP1, $P A G 11$, and $P D P N$ were accounted for in the model $(P=0.3)$. This suggests that effects of EB on embryo survival in cows with partial embryo losses are largely mediated via TKDP1, PAG11, and PDPN. This also provides candidate signaling pathways for the effect of EB on embryo growth to Day 15.

\section{CONCLUSIONS}

In the current study, bulk transfer of Day 7 IVP blastocysts resulted in embryos with considerable variation in length recovered $8 \mathrm{~d}$ later, even from the same uterine environment. Mathematical models of embryo survival allowed both uterine receptiveness and embryo quality factors on embryo survival to be described and allowed these dual components of the biology to be analyzed. The EG model presented here was validated using literature data and experimental data from this trial and provides a description of the complex interaction between progesterone and blastocyst developmental stage on embryo growth. The model provided good predictions of progesterone on days where progesterone was not measured. We used the model to estimate the time delay $(4.75 \pm 0.16 \mathrm{~d})$ between an increase in circulating progesterone and an increase in uterine competence. We also found that doubling progesterone increased the embryo growth rate by around 33\%. The EG model captured the main features of embryo growth kinetics

Table 3. Correlation matrix (variances in parentheses) for the estimated error variance-covariance matrix from the multivariate regression of the effect of progesterone on Day $7(\mathrm{ng} / \mathrm{mL})$, energy balance from transfer to recovery $(\mathrm{MJ} / \mathrm{d})$, and embryo transfer size (log 10 cells) on gene expression, ${ }^{1}$ embryonic disc area $\left(\mathrm{ED} ; \log _{10} \mu \mathrm{m}^{2}\right)$, and trophectoderm length (TL; $\log _{10} \mathrm{~mm}$ ) of Day 15 embryos.

\begin{tabular}{|c|c|c|c|c|c|c|c|c|}
\hline Gene & $I F N T$ & $T K D P 1$ & $P D P N$ & PTGS2 & $D K K 1$ & PAG11 & $\mathrm{ED}$ & TL \\
\hline$T K D P 1$ & & $1.00(0.10)$ & -0.51 & 0.72 & 0.47 & 0.67 & 0.52 & 0.67 \\
\hline$P D P N$ & & & $1.00(0.18)$ & -0.60 & -0.30 & -0.38 & -0.57 & -0.61 \\
\hline$D K K 1$ & & & & & $1.00(0.12)$ & 0.46 & 0.59 & 0.57 \\
\hline PAG11 & & & & & & $1.00(0.21)$ & 0.56 & 0.77 \\
\hline ED area & & & & & & & $1.00(0.12)$ & 0.70 \\
\hline
\end{tabular}

${ }^{1}$ Gene expression is expressed as $\log _{10}\left(\right.$ relative copy number $\left.\times 10^{3}\right)$. 
because it was able to predict the effect of progesterone and developmental stage on embryo growth for both literature data and our data, demonstrating its utility. Others have shown a clear relationship between the kinetics of development of early bovine embryos to first cleavage after insemination and developmental competence. However, we found that although Day 15 embryo size depends on the specific morphological stage (indicative of cell number or size) of the Day 7 blastocyst when it was transferred, progesterone is a more important factor than transferred embryo size on subsequent growth.

\section{ACKNOWLEDGMENTS}

We thank P. Sharpe (ET services, Hamilton, New Zealand) for sample collection; staff of AgResearch (Ruakura, Hamilton, New Zealand); staff of Tokanui Farm for animal husbandry; S. Delaney and C. Smith (AgResearch) for sample collection; S. Franke for technical assistance; and P. Hunt (AgResearch) for graphic arts. This work was supported by AgResearch Core funding.

\section{REFERENCES}

AFRC. 1993. Energy and Protein Requirements of Ruminants. An advisory manual prepared by the AFRC Technical Committee on Responses to Nutrients. CAB International, Wallingford, UK.

Bates, D. M., and D. G. Watts. 2007. Nonlinear Regression Analysis and its Applications. John Wiley \& Sons, New York, NY.

Bazer, F. W., R. M. Roberts, and W. W. Thatcher. 1979. Actions of hormones on the uterus and effect on conceptus development. J. Anim. Sci. 49:35-45.

Beam, S. W., and W. R. Butler. 1997. Energy balance and ovarian follicle development prior to the first ovulation postpartum in dairy cows receiving three levels of dietary fat. Biol. Reprod. 56:133-142.

Berg, D. K., J. van Leeuwen, S. Beaumont, M. Berg, and P. L. Pfeffer. 2010. Embryo loss in cattle between Days 7 and 16 of pregnancy. Theriogenology 73:250-260.

Betteridge, K. J., M. D. Eaglesome, G. C. B. Randall, and D. Mitchell. 1980. Collection, description and transfer of embryos from cattle 10-16 days after oestrous. J. Reprod. Fertil. 59:205-216.

Brandão, D. O., P. Maddox-Hyttel, P. Løvendahl, R. Rumpf, D. Stringfellow, and H. Callesen. 2004. Post hatching development: A novel system for extended in vitro culture of bovine embryos. Biol. Reprod. 71:2048-2055.

Burnham, K. P., and D. R. Anderson. 2002. Model Selection and Multimodel Selection. Springer, New York, NY.

Carter, F., N. Forde, P. Duffy, M. Wade, T. Fair, M. A. Crowe, A. C. Evans, D. A. Kenny, J. F. Roche, and P. Lonergan. 2008. Effect of increasing progesterone concentration from Day 3 of pregnancy on subsequent embryo survival and development in beef heifers. Reprod. Fertil. Dev. 20:368-375.

Clemente, M., J. de La Fuente, T. Fair, A. Al Naib, A. Gutierrez-Adan, J. F. Roche, D. Rizos, and P. Lonergan. 2009. Progesterone and conceptus elongation in cattle: a direct effect on the embryo or an indirect effect via the endometrium? Reproduction 138:507-517.

Diskin, M. G., and D. G. Morris. 2008. Embryonic and early foetal losses in cattle and other ruminants. Reprod. Domest. Anim. $43: 260-267$.
Fléchon, J. E., M. Guillomot, M. Charlier, B. Flechon, and J. Martal. 1986. Experimental studies on the elongation of the ewe blastocyst. Reprod. Nutr. Dev. 26:1017-1024.

Forde, N., M. E. Beltman, G. B. Duffy, P. Duffy, J. P. Mehta, P O'Gaora, J. F. Roche, P. Lonergan, and M. A. Crowe. 2011. Changes in the endometrial transcriptome during the bovine estrous cycle: effect of low circulating progesterone and consequences for conceptus elongation. Biol. Reprod. 84:266-278.

Forde, N., P. A. McGettigan, J. P. Mehta, L. O'Hara, S. Mamo, F. W Bazer, T. E. Spencer, and P. Lonergan. 2014. Proteomic analysis of uterine fluid during the pre-implantation period of pregnancy in cattle. Reproduction 147:575-587.

Garrett, J. E., R. D. Geisert, M. T. Zavy, and G. L. Morgan. 1988. Evidence for maternal regulation of early conceptus growth and development in beef cattle. J. Reprod. Fertil. 84:437-446.

Ghanem, N., D. Salilew-Wondim, A. Gad, D. Tesfaye, C. Phatsara, E. Tholen, C. Looft, K. Schellander, and M. Hoelker. 2011. Bovine blastocysts with developmental competence to term share similar expression of developmentally important genes although derived from different culture environments. Reproduction 142:551-564.

Gilks, W. R., A. Richardson, and D. J. Spiegelhalter. 1996. Markov Chain Monte Carlo in Practice. Chapman \& Hall, London, UK.

Gray, C. A., R. C. Burghardt, G. A. Johnson, F. W. Bazer, and T. E. Spencer. 2002. Evidence that absence of endometrial gland secretions in uterine gland knockout ewes compromises conceptus survival and elongation. Reproduction 124:289-300.

Green, J. A., S. Xie, X. Quan, B. Bao, X. Gan, N. Mathialagan, J. F. Beckers, and R. M. Roberts. 2000. Pregnancy-associated bovine and ovine glycoproteins exhibit spatially and temporally distinct expression patterns during pregnancy. Biol. Reprod. 62:1624-1631.

Gregory, N. G., J. K. Robins, D. G. Thomas, and R. W. Purchas. 1998. Relationship between body condition score and body composition in dairy cows. N. Z. J. Agric. Res. 41:527-532.

Guillomot, M., A. Turbe, I. Hue, and J. P. Renard. 2004. Staging of ovine embryos and expression of the T-box genes Brachyury and Eomesodermin around gastrulation. Reproduction 127:491-501.

Holm, P., P. J. Booth, and H. Callesen. 2002. Kinetics of early in vitro development of bovine in vivo- and in vitro-derived zygotes produced and/or cultured in chemically defined or serum-containing media. Reproduction 123:553-565.

Holm, P., N. N. Shukri, G. Vajta, P. Booth, C. Bendixen, and H. Callesen. 1998. Developmental kinetics of the first cell cycles of bovine in vitro produced embryos in relation to their in vitro viability and sex. Theriogenology 50:1285-1299.

Ledgard, A. M., M. C. Berg, W. H. McMillan, G. Smolenski, and A. J. Peterson. 2012. Effect of asynchronous transfer on bovine embryonic development and relationship with early cycle uterine proteome profiles. Reprod. Fertil. Dev. 24:962-972.

Ledgard, A. M., R. S. Lee, C. Couldrey, and A. J. Peterson. 2009 Dickkopf-1 expression during early bovine placentation and its down-regulation in somatic cell nuclear transfer (SCNT) pregnancies. J. Reprod. Dev. 55:467-474.

Ledgard, A. M., S. Meier, and A. J. Peterson. 2011. Evaluation of the uterine environment early in pregnancy establishment to characterise cows with a potentially superior ability to support conceptus survival. Reprod. Fertil. Dev. 23:737-747.

Lonergan, P., H. Khatir, F. Piumi, D. Rieger, P. Humblot, and M. P. Boland. 1999. Effect of time interval from insemination to first cleavage on the developmental characteristics, sex ratio and pregnancy rate after transfer of bovine embryos. J. Reprod. Fertil. 117:159-167.

Lonergan, P., P. Monaghan, D. Rizos, M. P. Boland, and I. Gordon. 1994. Effect of follicle size on bovine oocyte quality and developmental competence following maturation, fertilization, and culture in vitro. Mol. Reprod. Dev. 37:48-53.

Machado, G. M., A. R. Ferreira, I. B. Pivato, A. Fidelis, J. F. Spricigo, F. Paulini, C. M. Lucci, M. M. Franco, and M. A. Dode. 2013. Post-hatching development of in vitro bovine embryos from day 7 to 14 in vivo versus in vitro. Mol. Reprod. Dev. 80:936-947. 
Mann, G. E., M. D. Fray, and G. E. Lamming. 2006. Effects of time of progesterone supplementation on embryo development and interferon- $\tau$ production in the cow. Vet. J. 171:500-503.

Matsuyama, S., T. Kojima, S. Kato, and K. Kimura. 2012. Relationship between quantity of IFNT estimated by IFN-stimulated gene expression in peripheral blood mononuclear cells and bovine embryonic mortality after AI or ET. Reprod. Biol. Endocrinol. 10:21.

McMillan, W. H. 1998. Statistical models predicting embryo survival to term in cattle after embryo transfer. Theriogenology 50:10531070.

Morris, D., and M. G. Diskin. 2008. Effect of progesterone on embryo survival. Animal 2:1112-1119.

Nogales, F. F., and I. Dulcey. 2012. The secondary human yolk sac has an immunophenotype indicative of both hepatic and intestinal differentiation. Int. J. Dev. Biol. 56:755-760.

O’Hara, L., N. Forde, F. Carter, D. Rizos, V. Maillo, A. D. Ealy, A. K. Kelly, P. Rodriguez, N. Isaka, A. C. O. Evans, and P. Lonergan. 2014b. Paradoxical effect of supplementary progesterone between Day 3 and Day 7 on corpus luteum function and conceptus development in cattle. Reprod. Fertil. Dev. 26:328-336.

O'Hara, L., N. Forde, P. Duffy, F. Randi, A. K. Kelly, A. Valenza, P. Rodriguez, and P. Lonergan. 2016. Effect of combined exogenous progesterone with luteotrophic support via equine chorionic gonadotrophin (eCG) on corpus luteum development, circulating progesterone concentrations and embryo development in cattle. Reprod. Fertil. Dev. 28:269-277.

O'Hara, L., N. Forde, A. K. Kelly, and P. Lonergan. 2014a. Effect of bovine blastocyst size at embryo transfer on day 7 on conceptus length on day 14: Can supplementary progesterone rescue small embryos? Theriogenology 81:1123-1128.

Patel, O. V., O. Yamada, K. Kizaki, J. Todoroki, T. Takahashi, K. Imai, L. A. Schuler, and K. Hashizume. 2004. Temporospatial expression of placental lactogen and prolactin-related protein-1 genes in the bovine placenta and uterus during pregnancy. Mol. Reprod. Dev. 69:146-152.

Pavlok, A., A. Lucas-Hahn, and H. Niemann. 1992. Fertilization and developmental competence of bovine oocytes derived from different categories of antral follicles. Mol. Reprod. Dev. 31:63-67.

Pawitan, Y. 2001. In all likelihood: Statistical modelling and inference using likelihood. Oxford University Press, London.

Peters, A. R. 1996. Embryo mortality in the cow. Anim. Breed. Abstr. 64:587-598.

Pryce, J. E., B. L. Harris, W. A. Montgomerie, R. Jackson, K. A. Macdonald, C. B. Glassey, B. S. Thorrold, and C. W. Holmes. 2006. Comparing feed allowances to inferred energy intake using data from a dairy grazing farm trial. Proc. N.Z. Soc. Anim. Prod. 65:225-230.

Rencher, A. C. 2002. Methods of Multivariate Analysis. 2nd ed. John Wiley \& Sons Inc., New York, NY.

Restall, B. J., and D. A. Griffiths. 1976. Assessment of reproductive wastage in sheep. 2. Interpretation of data concerning embryonic mortality. Aust. J. Exp. Agric. Anim. Husb. 16:329-335.

Rizos, D., F. Carter, U. Besenfelder, V. Havlicek, and P. Lonergan. 2010. Contribution of the female reproductive tract to low fertility in postpartum lactating dairy cows. J. Dairy Sci. 93:1022-1029.

Roberts, S. A., W. M. Hirst, D. R. Brison, and A. Vail. 2010. Embryo and uterine influences on IVF outcomes: An analysis of a UK multi-centre cohort. Hum. Reprod. 25:2792-2802.

Robinson, R. S., M. D. Fray, D. C. Wathes, G. E. Lamming, and G. E. Mann. 2006. In vivo expression of interferon tau mRNA by the embryonic trophoblast and uterine concentrations of interferon tau protein during early pregnancy in the cow. Mol. Reprod. Dev. 73:470-474.

Roche, J. R., C. R. Burke, S. Meier, and C. G. Walker. 2011. Nutrition $\mathrm{x}$ reproduction interaction in pasture-based systems: Is nutrition a factor in reproductive failure? Anim. Prod. Sci. 51:1045-1066.

Sangsritavong, S., D. K. Combs, R. Sartori, L. E. Armentano, and W. C. Wiltbank. 2002. High feed intake increases liver blood flow and metabolism of progesterone and estradiol-17beta in dairy cattle. J. Dairy Sci. 85:2831-2842.

Satterfield, M. C., F. W. Bazer, and T. E. Spencer. 2006. Progesterone regulation of preimplantation conceptus growth and galectin 15 (LGALS15) in the ovine uterus. Biol. Reprod. 75:289-296.

Shorten, P. R., A. R. O'Connell, K. J. Demmers, S. J. Edwards, N. G. Cullen, and J. L. Juengel. 2013. Effect of age, weight, and sire on embryo and fetal survival in sheep. J. Anim. Sci. 91:4641-4653.

Shorten, P. R., A. J. Peterson, A. R. O'Connell, J. L. Juengel, K. P. McNatty, and T. K. Soboleva. 2010. A mathematical model of pregnancy recognition in mammals. J. Theor. Biol. 266:62-69.

Shorten, P. R., T. K. Soboleva, A. B. Pleasants, and J.-M. Membre. 2006. A risk assessment approach applied to the growth of Erwinia carotovora in vegetable juice for variable temperature conditions. Int. J. Food Microbiol. 109:60-70.

Smith, C. S., D. K. Berg, M. Berg, S. Beaumont, N. T. Standley, D. N. Wells, and P. L. Pfeffer. 2007. Simultaneous gene quantitation of multiple genes in individual bovine nuclear transfer blastocysts. Reproduction 133:231-242.

Smith, C. S., D. K. Berg, M. Berg, and P. L. Pfeffer. 2010. Nuclear transfer-specific defects are not apparent during the second week of embryogenesis in cattle. Cell. Reprogram. 12:699-707.

Spencer, T. E. 2013. Early pregnancy: Concepts, challenges, and potential solutions. Anim. Front. 3:48-55.

Spencer, T. E., G. A. Johnson, F. W. Bazer, R. C. Burghardt, and M. Palmarini. 2007. Pregnancy recognition and conceptus implantation in domestic ruminants: Roles of progesterone, interferons and endogenous retroviruses. Reprod. Fertil. Dev. 19:65-78.

Spencer, T. E., G. A. Johnson, R. C. Burghardt, and F. W. Bazer. 2004. Progesterone and placental hormone actions on the uterus: Insights from domestic animals. Biol. Reprod. 71:2-10.

Stronge, A. J. H., J. M. Sreenan, M. G. Diskin, J. F. Mee, D. A. Kenny, and D. G. Morris. 2005. Post insemination milk progesterone concentration and embryo survival in dairy cows. Theriogenology 64:1212-1224.

Thompson, I. M., R. L. Cerri, I. H. Kim, A. D. Ealy, P. J. Hansen, C. R. Staples, and W. W. Thatcher. 2012. Effects of lactation and pregnancy on metabolic and hormonal responses and expression of selected conceptus and endometrial genes of Holstein dairy cattle. J. Dairy Sci. 95:5645-5656.

Tsai, S. J., and M. C. Wiltbank. 1998. Prostaglandin $\mathrm{F}_{2 \alpha}$ regulates distinct physiological changes in early and mid-cycle bovine corpora lutea. Biol. Reprod. 58:346-352.

Ulbrich, S. E., E. Wolf, and S. Bauersachs. 2012. Hosting the preimplantation embryo: potentials and limitations of different approaches for analysing embryo-endometrium interactions in cattle. Reprod. Fertil. Dev. 25:62-70.

Ushijima, H., K. Akiyama, and T. Tajima. 2009. Classification of morphological changes based on the number of cleavage divisions in bovine embryos. J. Reprod. Dev. 55:83-87.

Valour, D., S. A. Degrelle, A. A. Ponter, C. Giraud-Delville, E. Campion, C. Guyader-Joly, C. Richard, F. Constant, P. Humblot, C. Ponsart, I. Hue, and B. Grimard. 2014. Energy and lipid metabolism gene expression of D18 embryos in dairy cows is related to dam physiological status. Physiol. Genomics 46:39-56.

van Leeuwen, J., D. K. Berg, and P. L. Pfeffer. 2015. Morphological and gene expression changes in cattle embryos from hatched blastocyst to early gastrulation stages after transfer of in vitro produced embryos. PLoS One 10:e0129787.

Watson, A. J., A. Hogan, A. Hahnel, K. E. Wiemer, and G. A. Schultz. 1992. Expression of growth factor ligand and receptor genes in the preimplantation bovine embryo. Mol. Reprod. Dev. 31:87-95.

Wilkening, S., and A. Bader. 2004. Quantitative real-time polymerase chain reaction: Methodical analysis and mathematical model. J. Biomol. Tech. 15:107-111. 